\title{
Effects of LED Light Illumination on Germination, Growth and Anthocyanin Content of Dandelion (Taraxacum officinale)
}

\author{
Jai Hyunk Ryu ${ }^{1,2}$, Kyoung Sun $\mathrm{Seo}^{3}$, Gab Lim Choi ${ }^{4}$, Eui Shik Rha ${ }^{1}$, Sheong Chun Lee ${ }^{1}$, \\ Seong Kyu Choi ${ }^{5}$, Si-Yong Kang ${ }^{2}$ and Chang-Hyu Bae ${ }^{1}$ * \\ ${ }^{1}$ Department of Bioresources Science, Sunchon National University, Suncheon 540-742, Korea \\ ${ }^{2}$ Advanced Radiation Technology Institute, Korea Atomic Energy Research Institute, Jeongup 580-185, Korea \\ ${ }^{3}$ Jangheung-county Mushroom Research Institute, Jangheung 529-851, Korea \\ ${ }^{4}$ Korea Institute of Ecology and Environment (KIEE), Daejeon 305-325, Korea \\ ${ }^{5}$ Department of Development in Oriental Medicine Resource, Sunchon National University, Suncheon 540-742, Korea
}

\begin{abstract}
Dandelion has been widely utilized for medicinal and edible purposes. This research was conducted to evaluate the effect of supplemental LED (light-emitting diode) light on germination, growth characteristics and anthocyanin content of dandelion (Taraxacum officinale) seedling using LED blue $(460 \mathrm{~nm})$, red $(660 \mathrm{~nm}, \mathrm{R})$, blue + red $(\mathrm{B}: \mathrm{R}=6: 4)$ and fluorescent lamp light treatment. By LED illumination to T. officinale seed germination speed was delayed, and germination rate was the highest in the fluorescent light. The growth characteristics (plant height, number of leaves, root length and fresh weight) were greatly influenced by supplemental LED light compared with control treatment, and the growth promotion was the most effective in the red LED illumination. After 60 days of red and mixed LED light treatments, anthocyanin content of dandelion plants was significantly changed. The anthocyanin content was increased by $12 \sim 19 \mathrm{mg} / 100 \mathrm{~g}$ under the red LED and the mixed light conditions compared with the control and the blue LED. Results indicate that illumination with red and mix LEDs, compared with other light treatments, is beneficial for promotion of growth and anthocyanin content in dandelion.
\end{abstract}

Key words - Dandelion, LED illumination, Growth, Anthocyanin

\section{Introduction}

Plants of the genus Taraxacum, also known as dandelions, are members of the Asteraceae family. These perennial plants are widespread throughout the warmer temperate zones of the Northern Hemisphere and have been used for centuries as a remedy for various ailments by several societies. Dandelion in Korea could be used as the traditional oriental medicine, having anti-infection effect, diuretic, and removal of fever according to the Korea herbal pharmacopoeia (Korea Food \& Drug Administration. 2011), and native Americans use dandelion roots and herbs to treat kidney disease, dyspepsia and heartburn. In traditional Arabian medicine, dandelions have been applied to remedy liver and spleen disorders, whereas European herbalists authorize the use of dandelions for fever, boils, eye problems, diabetes and diarrhea (Akashi

*Corresponding author. E-mail : chbae@sunchon.ac.kr et al., 1994; Korea Food \& Drug Administration, 2011; Williams et al., 1996).

Light-emitting diodes (LEDs) have a variety of advantages over traditional forms lighting. Their small size, durability, long lifetime, cool emitting temperature and the option to select specific wavelengths for a targeted plant response make LEDs more suitable for plant-based uses than many other light sources (Chory et al., 1996; Kopsell and Kopsell, 2008). These advantages, coupled with new developments in wavelength availability, light output and energy conversion efficiency, place us on the brink of a revolution in lighting. Light quality plays a major role in the appearance and productivity of ornamental and food specialty crop species (Chory et al., 1996; Coombe, 1973; Giliberto et al., 2005; Ryu et al., 2012). Far-red light, for example, is important for stimulating flowering of long-day plants (Cho et al., 2011; Fankhauser and Chory, 1997) as well as for promoting internode elongation (Kopsell and Kopsell, 2008; Nishimura et 
al., 2008). Blue light is important for phototropism (Giliberto et al., 2005; Tanaka et al., 1998) for stomatal opening and for inhibiting seedling growth on emergence of seedlings from a growth medium (Masson et al., 1991). The blue light photoreceptor class of cryptochromes has been found to work in conjunction with the red/FR phytochrome photoreceptor class to control factors such as circadian rhythms and de-etiolation in plants (Giliberto et al., 2005). The interactions are complex and continue to be unraveled at the molecular level (Kopsell and Kopsell, 2008), but much of our understanding of these responses comes from studies with narrow-waveband lighting sources, in which LEDs provide obvious advantages.

Anthocyan (anthocyanins and glycosylated anthocyanidins) are water-soluble, vacuolar pigments responsible for the violet, blue, purple, red and scarlet colors of stems, leaves, flowers and fruits in the vast majority of higher plants (Keppler and Humpf, 2005; Ribereau-Gayon and RibereauGayon. 1958). The anthocyanins are part of a class of chemically related pigments, the flavonoids, which includes flavonols, flavanones, flavones, catechins, chalkones and anthocyanins (Meng et al., 2004). Anthocyanin was of particular interest to the food colorant industry due to their ability to impart vibrant colors. Anthocyanin have been incorporated into the human diet for centuries and have been used as traditional herbal medicines due to their diverse physiological abilities to treat conditions such as hypertension, pyrexia, liver disorders, dysentery and diarrhea, urinary problems and the common cold. Light-dependent anthocyanin synthesis has been extensively used as a model system for studies of the mechanism of photoregulation of plant development (Giusti and Wrolstad, 2005; Keppler and Humpf, 2005; Meng et al., 2004).

The objective of our studies was to evaluate the germination, growth and anthocyanin content of dandelion that cultivated under various LED lamps.

\section{Materials and Methods}

\section{Plant materials and growing condition}

Dandelion seeds (T. officinale cv. Goldenboll) were sown in a plastic pots (diameter $20 \mathrm{~cm}$ and depth $20 \mathrm{~cm}$ ) containing a commercial soil mixture (Bio 1ho, Heungnong Co. Korea) with six replications, and the distance among the seeds (50 ea) was $2 \mathrm{~cm}$. The dandelions were sub-irrigated with tap water without any nutritional solutions during the experimental period throughout the growing period. Temperature was maintained at $25 \pm 2{ }^{\circ} \mathrm{C}$ and relative humidity was $50 \%$ during germination in growth room. This experiment was carried out from July to August in 2011 at glass house of Sunchon National University, South Korea.

\section{Supplemental light treatments}

A LED light panel consists of LED sticks with a main controller and LEDs were used for supplemental light source and placed horizontally $75 \mathrm{~cm}$ above the plant canopy (Dyne Bio, Korea). The experiments composed of four treatments with different supplementary LEDs wavelengths: red (R) 660 $\mathrm{nm}$, blue $460 \mathrm{~nm}$, a combination of blue and red light (BR

Table 1. Operation conditions for anthocyanin analysis of LED irradiated T. officinale cv. Goldenboll

\begin{tabular}{cl}
\hline \hline Items & \multicolumn{1}{c}{ Operation conditions } \\
\hline Instrument & Waters associates M 510 \\
Detector & UV 486 detector $520 \mathrm{~nm}$ (Waters Co., U.S.A) \\
Column & Symmetry C18, $5 \mu \mathrm{m}(3.9 \times 150 \mathrm{~mm})$ \\
Mobile phase & $\mathrm{A}: 5 \%$ formic acid (Water) \\
& $\mathrm{B}: 5 \%$ formic acid (Acetonitrile $\mathrm{v} / \mathrm{v})$ \\
Gradient condition & $1-2 \mathrm{~min}: \mathrm{B}$ solution $(5 \%)$ \\
& $3-30 \mathrm{~min}: \mathrm{B}$ solution $(15-45 \%)$ \\
Column temp. & $30-40 \mathrm{~min}:$ B solution $(15 \%)$ \\
Flow rate & $30{ }^{\circ} \mathrm{C}$ \\
Injection volume & $1.0 \mathrm{ml} / \mathrm{min}$ \\
\hline
\end{tabular}


mixed B 6:R 4 in energy ratio), fluorescent lamp as a control. Dandelion seedlings were grown for 60 days with photosynthetic photon flux (PPF) maintained at $38 \pm 2 \mu \mathrm{mol} / \mathrm{m}^{2} / \mathrm{s}$. Photoperiod of the light treatments was 14 hours per day. To prevent light contamination, non reflective black unwoven fabric was placed inside frame.

\section{Measurements}

At 18 days after germination of dandelion 50 seedlings of each boxes were collected to evaluate the growth characteristics such as plant height, number of leaves, root length and plant fresh weight. Anthocyanin content of each treatment was analyzed with 20 samples of each plot.

\section{Determination of anthocyanin content}

The extraction protocols described by Kim (1999) were used. Samples $(10 \mathrm{~g})$ were extracted with $50 \mathrm{ml}$ (Ethanol: $\mathrm{H}_{2} \mathrm{O}: \mathrm{HCl}=20: 79: 1$ ) for $12 \mathrm{~h}$. The liquid extract was separated by centrifugation at $3000 \mathrm{rpm}$ for 30 minutes. After both solutions were filtered $(0.45 \mu \mathrm{m}$ membrane filter $)$ and the extract was used for HPLC analysis (Table 1).

\section{Statistical analysis}

This experiment was designed as randomized block design with six replications. One-way analyses of variance were performed using SPSS software (version 12; SPSS Inc, USA) along with Duncan's multiple range tests to compare differences among mean values. Mean values and standard deviation were reported, and the significance was defined at $P<0.05$.

\section{Results}

\section{Effect of supplemental light qualities on germination rate} (\%)

The germination rates (\%) obtained from various LED light treatments were shown in Fig. 1. The average day required for germination was longer in LED light treatment than control. Germination speed was also slower in LED treatment than that of control. At three to eighteen days after sowing, the germination rate under fluorescent light treatment was higher than that of LED treatments over 8 to 9.7 percent. At 18 days after sowing, germination rate of dandelion under blue, red, mixed LED light and fluorescent lamp was $74.0 \%$, $77.3 \%, 75.7$ and $83.7 \%$, respectively.

\section{Effect of supplemental light qualities on growth characteristics of dandelion}

Growth characteristics of dandelion seedlings were greatly influenced by different supplemental LED light treatments. The plant height of dandelion grown under various LED light is presented in Table 2. At all growth stages, plant height was highest in red LED treatment. The plant height of red LED was more two times higher than that of control at 20 to 30 days after LED treatment. After 60 days of seeding, plant

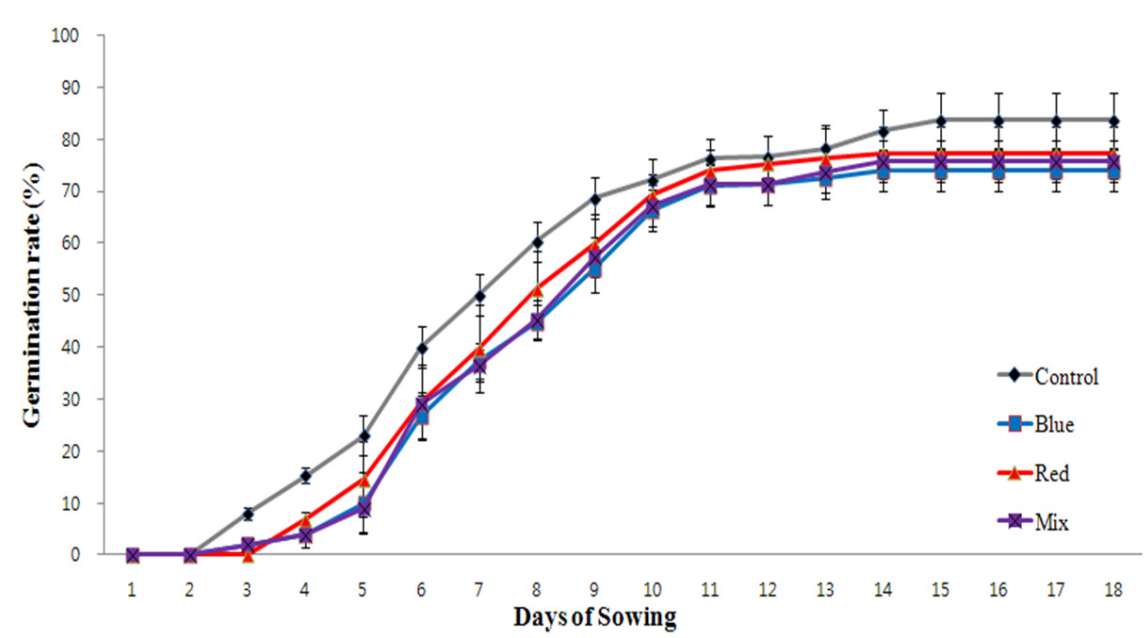

Fig. 1. Germination rate of $T$. offinale cv. Goldenboll seed under different light quality during germination. Values are represented mean $\pm \mathrm{SD}(\mathrm{n}=6)$. 
height of dandelion grown under blue, red, mixed LED light and fluorescent lamp was 23.10, 26.63, 23.18 and $19.74 \mathrm{~cm}$, respectively.

Table 3 shows the changes of number of leaves of dandelion grown under the supplementary LED lighting. Number of leaves was significantly increased by LED treatment than control, and red LED treatment was most effective in promotion of number of leaves. Especially, blue, red and mixed LED treatment significantly promoted an increase of leaf number by $4.2 \%, 6.8 \%$ and $5.5 \%$, respectively, compared with control treatment.

The root length increased significantly with red LED treatment during whole growth periods. Root length of dandelion grown under blue, red, mixed LED and fluorescent lamp was $8.82,9.24,8.47$ and $8.20 \mathrm{~cm}$, respectively, at sixty days after seeding (Table 4).

Figure 2 shows the changes of fresh weight of dandelion grown under the supplementary LED lighting. Fresh weight was significantly increased by LED treatment than that of control at sixty days after seeding. Red LED treatment

Table 2. Plant height of $T$. officinale cv. Goldenboll as affected by various kinds of light qualities of LED illumination

$(\mathrm{cm})$

\begin{tabular}{ccccccc}
\hline \hline \multirow{2}{*}{ Treatment } & \multicolumn{5}{c}{ Days after LED irradiation } \\
\cline { 2 - 7 } & 10 & 20 & 30 & 40 & 50 & 60 \\
\hline Cont & $0.93 \pm 0.02^{\text {cy }}$ & $1.72 \pm 0.23^{\mathrm{d}}$ & $4.69 \pm 1.19^{\mathrm{d}}$ & $8.32 \pm 1.19^{\mathrm{d}}$ & $15.4 \pm 2.19^{\mathrm{c}}$ & $19.74 \pm 3.01^{\mathrm{c}}$ \\
Blue LED & $0.98 \pm 0.05^{\mathrm{b}}$ & $2.50 \pm 0.27^{\mathrm{b}}$ & $5.79 \pm 1.24^{\mathrm{c}}$ & $10.2 \pm 1.91^{\mathrm{b}}$ & $18.9 \pm 2.79^{\mathrm{b}}$ & $23.10 \pm 2.62^{\mathrm{b}}$ \\
Red LED & $1.33 \pm 0.09^{\mathrm{a}}$ & $4.50 \pm 0.98^{\mathrm{a}}$ & $9.58 \pm 1.80^{\mathrm{a}}$ & $14.0 \pm 2.12^{\mathrm{a}}$ & $21.2 \pm 3.19^{\mathrm{a}}$ & $26.63 \pm 3.65^{\mathrm{a}}$ \\
Mix LED $^{\mathrm{z}}$ & $0.98 \pm 0.02^{\mathrm{b}}$ & $2.30 \pm 0.24^{\mathrm{c}}$ & $5.94 \pm 1.27^{\mathrm{b}}$ & $9.78 \pm 1.61^{\mathrm{c}}$ & $18.6 \pm 2.15^{\mathrm{b}}$ & $23.18 \pm 3.14^{\mathrm{b}}$ \\
\hline
\end{tabular}

${ }^{\mathrm{z}}$ Cont: Mix LED: Blue and Red (6:4) illumination.

${ }^{\mathrm{y}}$ Duncan's multiple range test at $5 \%$ level. Values in each column are mean $\pm \operatorname{SD}(\mathrm{n}=6)$.

Table 3. Number of leaves of T. officinale cv. Goldenboll as affected by various kind of light qualities of LED illumination

(ea)

\begin{tabular}{ccccccc}
\hline \hline \multirow{2}{*}{ Treatment } & \multicolumn{5}{c}{ Days after LED irradiation } \\
\cline { 2 - 7 } & 10 & 20 & 30 & 40 & 50 & 60 \\
\hline Cont & $2.33 \pm 0.55^{\text {dy }}$ & $3.55 \pm 0.71^{\mathrm{c}}$ & $5.98 \pm 1.46^{\mathrm{a}}$ & $6.23 \pm 1.85^{\mathrm{b}}$ & $6.54 \pm 1.51^{\mathrm{d}}$ & $6.9 \pm 1.56^{\mathrm{d}}$ \\
Blue LED & $2.44 \pm 0.62^{\mathrm{c}}$ & $3.77 \pm 0.68^{\mathrm{b}}$ & $5.23 \pm 1.54^{\mathrm{c}}$ & $5.98 \pm 1.45^{\mathrm{c}}$ & $6.79 \pm 1.56^{\mathrm{c}}$ & $7.2 \pm 1.78^{\mathrm{c}}$ \\
Red LED & $2.77 \pm 0.59^{\mathrm{a}}$ & $4.30 \pm 0.56^{\mathrm{a}}$ & $5.60 \pm 1.85^{\mathrm{b}}$ & $6.38 \pm 1.85^{\mathrm{a}}$ & $6.92 \pm 1.94^{\mathrm{a}}$ & $7.4 \pm 1.95^{\mathrm{a}}$ \\
Mix LED $^{\mathrm{z}}$ & $2.57 \pm 0.57^{\mathrm{b}}$ & $4.30 \pm 0.74^{\mathrm{a}}$ & $5.50 \pm 1.05^{\mathrm{b}}$ & $6.42 \pm 1.52^{\mathrm{a}}$ & $6.67 \pm 1.58^{\mathrm{b}}$ & $7.3 \pm 1.57^{\mathrm{b}}$ \\
\hline
\end{tabular}

${ }^{\mathrm{z}}$ Mix LED: Blue and Red (6:4) illumination.

${ }^{\mathrm{y}}$ Duncan's multiple range test at $5 \%$ level. Values in each column are mean $\pm \operatorname{SD}(n=6)$.

Table 4. Root length of $T$. officinale cv. Goldenboll as affected by various kind of light qualities of LED illumination

$(\mathrm{cm})$

\begin{tabular}{ccccccc}
\hline \hline \multirow{2}{*}{ Treatment } & \multicolumn{5}{c}{ Days after LED irradiation } \\
\cline { 2 - 7 } & 10 & 20 & 30 & 40 & 50 & 60 \\
\hline Cont & $0.94 \pm 0.01^{\mathrm{cy}}$ & $1.51 \pm 0.31^{\mathrm{b}}$ & $3.56 \pm 0.79^{\mathrm{c}}$ & $6.03 \pm 0.52^{\mathrm{c}}$ & $7.66 \pm 0.97^{\mathrm{c}}$ & $8.20 \pm 1.46^{\mathrm{c}}$ \\
Blue LED & $0.98 \pm 0.01^{\mathrm{b}}$ & $1.54 \pm 0.36^{\mathrm{a}}$ & $3.89 \pm 0.62^{\mathrm{b}}$ & $6.08 \pm 0.61^{\mathrm{b}}$ & $7.94 \pm 1.04^{\mathrm{b}}$ & $8.82 \pm 1.54^{\mathrm{b}}$ \\
Red LED & $1.01 \pm 0.02^{\mathrm{a}}$ & $1.58 \pm 0.44^{\mathrm{a}}$ & $4.02 \pm 0.96^{\mathrm{a}}$ & $6.98 \pm 1.03^{\mathrm{a}}$ & $8.31 \pm 1.42^{\mathrm{a}}$ & $9.24 \pm 1.49^{\mathrm{a}}$ \\
Mix LED $^{\mathrm{z}}$ & $0.99 \pm 0.01^{\mathrm{b}}$ & $1.52 \pm 0.34^{\mathrm{a}}$ & $3.83 \pm 0.78^{\mathrm{b}}$ & $6.04 \pm 0.82^{\mathrm{c}}$ & $7.67 \pm 1.05^{\mathrm{b}}$ & $8.47 \pm 1.15^{\mathrm{c}}$ \\
\hline
\end{tabular}

${ }^{\mathrm{z}}$ Mix LED: Blue and Red (6:4) illumination.

${ }^{\mathrm{y}}$ Duncan's multiple range test at $5 \%$ level. Values in each column are mean $\pm \operatorname{SD}(n=6)$. 


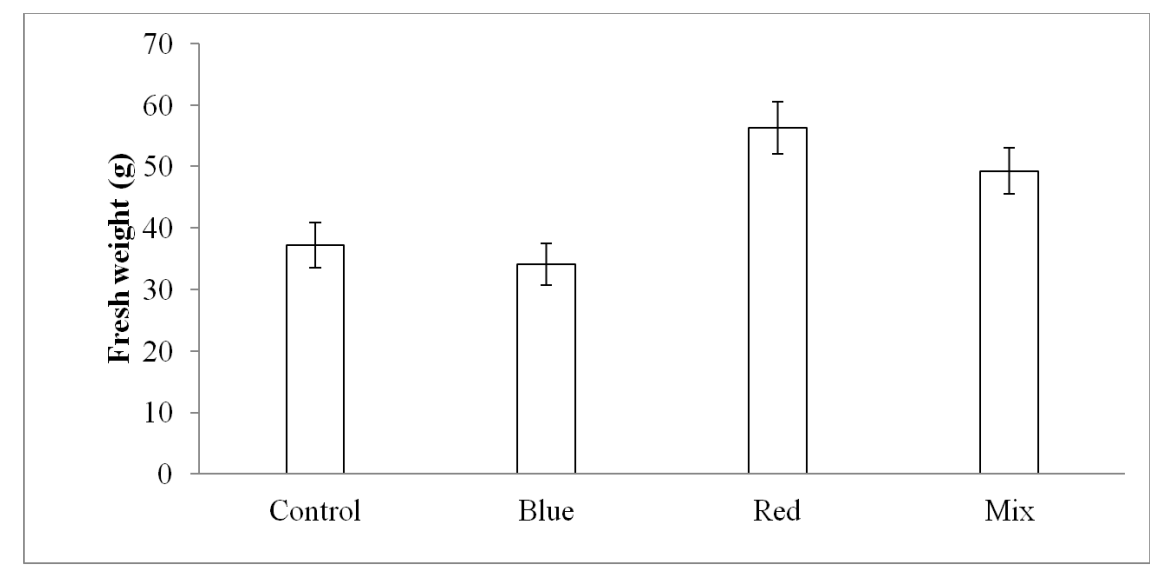

Fig. 2. Fresh weight of $T$. officinale $\mathrm{cv}$. Goldenboll as affected by various kind of light qualities of LED illumination (n=6).

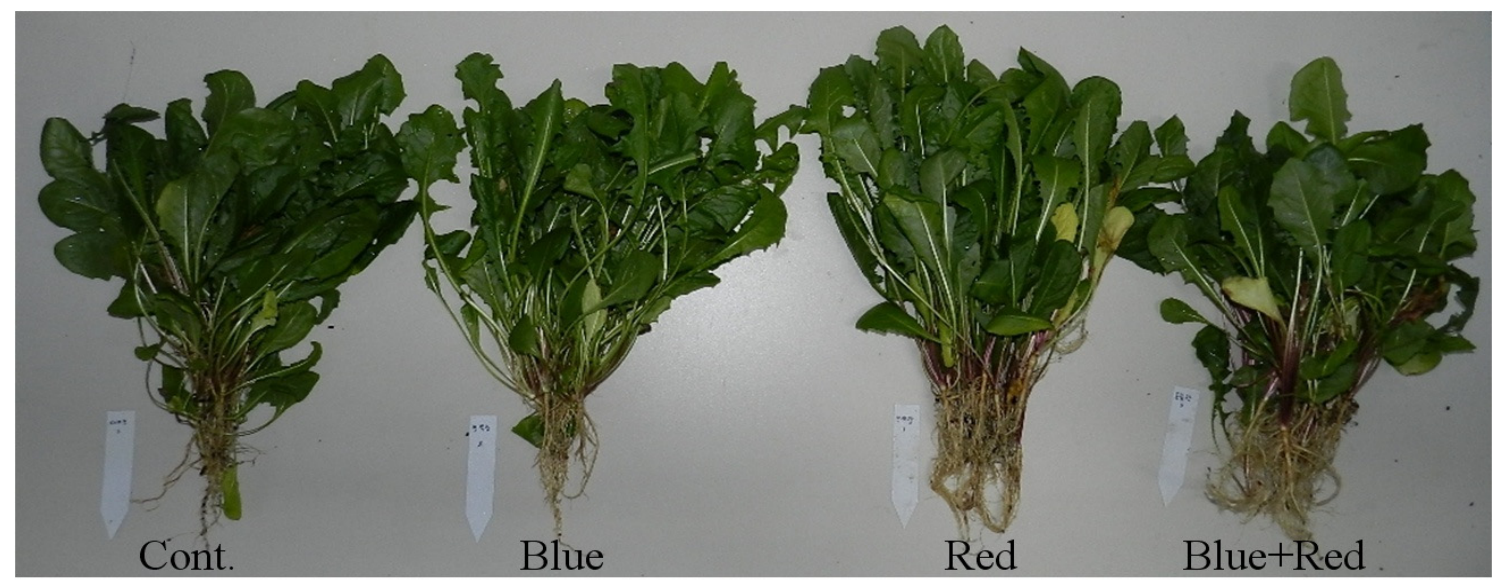

Fig. 3. One hundred plants of $T$. officinale cv. Goldenboll at 60 days after LED irradiation with different light qualities.

showed the heaviest fresh weight with an average of $66.93 \mathrm{~g}$, followed by blue $55.16 \mathrm{~g}$, mixed $54.43 \mathrm{~g}$, control $42.43 \mathrm{~g}$, respectively. At LED treatment, fresh weight was promoted by 24 to 36 percentages than that of control (Fig. 2, Fig. 3).

Table 5. Contents of anthocyanin from T. officinale cv. Goldenboll cultivated with different kind of LED illumination

\begin{tabular}{cc}
\hline \hline Samples & Contents $(\mathrm{mg} / 100 \mathrm{~g})$ \\
\hline Control $^{\mathrm{z}}$ & $37.24 \pm 3.69^{\mathrm{x}}$ \\
Blue LED & $34.10 \pm 3.43$ \\
Red LED & $56.24 \pm 4.21$ \\
Mix LED $^{\mathrm{y}}$ & $49.27 \pm 3.76$ \\
\hline
\end{tabular}

${ }^{\mathrm{z}}$ Control: Fluorescent lamp illumination.

${ }^{\mathrm{y}}$ Mix LED: Blue and Red (6:4) illumination.

${ }^{\mathrm{x}}$ All values are mean $\pm \mathrm{SD}(\mathrm{n}=3)$.

\section{Effect of supplemental light qualities on anthocyanin content of dandelion leaf}

The anthocyanin concentration of dandelion leaf grown under various LED light is presented in Table 5. At sixty days after seeding, anthocyanin content of dandelion leaf grown under blue, red, mixed LED and fluorescent lamp was 34.10, $56.24,49.27$ and $37.24 \mathrm{mg} / 100 \mathrm{~g}$, respectively. Anthocyanin concentration was significantly increased by red and mixed LED treatment, and there was no significant difference among the blue LED treatments and control (Table 5). These results indicate that red and mixed wave length is required for the production of anthocyanin in dandelion leaf.

\section{Discussion}

Effect of supplemental LED qualities on growth chara- 
cteristics and anthocyanin content of dandelion was observed. By LED irradiation to dandelion, an early seed germination speed was delayed, and the average days required for germination were longer in LED light treatment than that of control indicating that it has inhibitory effect on dandelion seed germination. This result generally agree with the findings of Jeon et al. (2010) that germination of Taraxacum platycarpum was significantly decreased with red $660 \mathrm{~nm}$, blue $460 \mathrm{~nm}$ and a combination of blue and red light (BR mixed B $6:$ R 4 in energy ratio) LED treatment compared with dark and fluorescent lamp.

The growth characteristics, such as plant height, number of leaves, root length and fresh weight were increased under the LED treatments compared with the control, and the growth promotion was the most effective in the red LED irradiation. Overalls, the plant height, number of leaves, root length and plant fresh weight were significantly increased by $26 \%$, $6.8 \%, 21 \%$ and $36 \%$, respectively, with the supplemental red light compared with control treatment. This finding concurs with previous studies that growth characteristics increased by the red LED treatments was detected in Lactuca sativa (Lee et al., 2010) and Capsicum annuum (Azad et al., 2011). Red light may increase starch accumulation in several plant species by inhibiting the translocation of photosynthates out of leaves (Tanaka et al., 1998; Saebo et al., 1995; Azad et al., 2011). In contrast, blue light is important in the formation of chlorophyll (Senger, 1982), chloroplast development (Akoyunoglou and Anni, 1984), stomatal opening (Zeiger, 1984) and enzyme synthesis (Senger, 1982). These different growth responses to red or blue LED light are most likely due to the different actions of phytochrome and cryptochrome photoreceptors, as suggested by previous studies (Doi et al., 2004; Smith, 2000).

Anthocyanins that accumulate in plants do not participate in primary photosynthetic reactions in chloroplasts, and formation of anthocyanins is a genetically determined by phytochrome mediated process requiring photosynthetic activity (Meng et al., 2004). Light is one of the main determinants of anthocyanin production, and anthocyanin biosynthesis is strongly dependent on light intensity or light quality (Giusti and Wrolstad, 2005; Keppler and Humpf, 2005). In particular, when the different ecotypes were kept at different R/FR ratios, the anthocyanin level was significantly increased under higher R/FR ratios, and the pigment levels were almost the same under low R/FR ratios (Alokam et al., 2002). In our study, anthocyanin content was significantly increased in 24 $\sim 33 \%$ with supplemental red and mixed red light treatments. And previous research shown that supplemental red light or a combination of supplemental red and blue lights (mix), compared with the control, significantly increased the anthocyanin concentration in leaf red lettuce; control $180 \mathrm{mg} / 100 \mathrm{~g}$, red $200 \mathrm{mg} / 100 \mathrm{~g}$, mix $250 \mathrm{mg} / 100 \mathrm{~g}$ (Lee et al., 2010), and pepper; control $1.1 \mathrm{mg} / 100 \mathrm{~g}$, red $5.5 \mathrm{mg} / 100 \mathrm{~g}$, mix $7.3 \mathrm{mg} /$ $100 \mathrm{~g}$ (Azad et al., 2011). Red light seems to be most effective in anthocyanin production (Zhou and Singh, 2002). In contrast, blue light increased levels of anthocyanins in tomato (Giliberto et al., 2005) and Capsicum annuum (Azad et al., 2011). More studies are needed to clarify the mechanisms of anthocyanin production. In addition, Ryu et al. (2012) reported that DPPH radical scavenging activity and SOD activity of leaf extracts of dandelion that was grown for 60 days under red and mixed LED treatment were higher than fluorescent lamp. Also, contents of total polyphenols and amino acids were significantly increased by red and mix LED treatment than those of fluorescent lamp (Ryu, 2012; Ryu et al., 2012). The information generated from this study gives a red light to be most effective in dandelion growth and anthocyanin production. And the results suggest that possibility to develop to produce high-value plant resources by using the dandelion.

\section{Acknowledgement}

This work was supported by Korea Institute of Planning and Evaluation for Technology in Food, Agriculture, Forestry and Fisheries (No. 110040-2).

\section{Literature Cited}

Akashi, T., T. Furuno, T. Takahashi and S.I. Ayabe. 1994. Biosynthesis of triterpenoids in cultured cells, and regenerated and wild plant organs of Taraxacum officinale. Phytochemistry 36:303-308.

Akoyunoglou, G. and H. Anni. 1984. Blue light on chloroplast development in higher plants. In Senger, H. (ed.), Blue Light 
in Biological Systems. Springer-Verlag, Berlin, West Germany. pp. 397-406.

Alokam, S., C.C. Chinnappa and D.M. Reid. 2002. Red/far-red light mediated stem elongation and anthocyanin accumulation in Stellaria longipes: Differential response of alpine and prairie ecotypes. Can. J. Bot. 80:72-81.

Azad, M.O.K., I.J. Chun, J.H. Jeong, S.T. Kwon and J.M. Hwang. 2011. Response of the growth characteristics and phytochemical contents of pepper (Capsicum annuum L.) seedlings with supplemental LED light in glass house. Bio-Environment Cont. 20(3):182-188.

Cho, J.Y., D.M. Son, J.M. Kim, B.S Seo, S.Y. Yang, B.W. Kim and B.G. Heo. 2011. Effects of various LEDs on the seed germination, growth and physiological activities of rape (Brassica napus) sprout vegetable. Plant Res. 21(4): 304-309 (in Korean).

Chory, J., R.K. Cook, T. Elich, C. Fankhauser, J. Li, P. Nagpal, M. Neff, A. Pepper, D. Poole, J. Reed and V. Vitart. 1996. From seed germination to flowering, light controls plant development via the pigment phytochrome. Proc. Natl. Acad. Sci. 93:12066-12071.

Coombe, B.R. 1973. The hormone content of ripening berries and the effects of growth substance treatments. Plant Physiol. 51:629-634.

Doi, M., A.T.E. Shigenaka, T. Kinoshita and K. Shimazaki. 2004. A transgene encoding a blue-light receptor, phot1, restores blue-light responses in the Arabidopsis phot1 phot2 double mutant. J. Exp. Bot. 55:517-523.

Giliberto, L., G. Perrotta, P. Pallara, J.L. Weller, P.D. Fraser, P.M. Bramley, A. Fiore, M. Tavazza and G. Giuliano. 2005. Manipulation of the blue light photoreceptor cryptochrome 2 in tomato affects vegetative development, flowering time, and fruit antioxidant content. Plant Physiol. 137: 199-208.

Giusti, M.M. and R.E. Wrolstad. 2005. Characterization and measurement of anthocyanins by UV-visible spectroscopy. In Wrolstad, R.E., T.E. Acree, E.A. Decker, M.H. Penner, D.S. Reid, S.J. Schwartz, C.F. Shoemaker, D. Smith and P. Sporns (eds.), Handbook of Food Analytical Chemistry: pigments, colorants, flavors, texture, and bioactive food components. John Wiley \& Sons, Hoboken, N.J., USA. pp. 19-31.

Jeon, S.H., D. Son, Y.S. Ryu, S.H. Kim, J.I. Chung, M.C. Kim and S.I. Shim. 2010. Effect of presowing seed treatments on germination and seedling emergence in Taraxacum platycarpum. Medicinal Crop Sci. 18(1):9-14 (in Korean).
Keppler, K. and H.U. Humpf. 2005. Metabolism of anthocyanins and their phenolic degradation products by the intestinal microflora. Bioorganic \& Medicinal Chem. 13: 5195-5205.

Kim, Y.H. 1999. Stabilities of anthocyanin pigments obtained from crab apple (Malus prunifolia Wild. Borkh. "Red Fruit") by ethanol extraction. Food Nutr. 12(1): 85-90 (in Korean).

Kopsell, D.A. and D.E. Kopsell. 2008. Genetic and environmental factors affecting plant lutein/zeaxanthin. Agro. Food Ind. Hi-Tech. 19:44-46.

Korea Food and Drug Administration. 2011. The Korea Herbal Pharmacopoeia. Taraxaci Herba. Korea Food and Drug Administration Announcement no. 2011-26. p. 376.

Lee, J.G., S.S. Oh, S.H. Cha, Y.A. Jang, S.Y. Kim, Y.C. Um and S.R. Cheong. 2010. Effects of red/blue light ratio and short-term light quality conversion on growth and anthocyanin contents of baby leaf lettuce. Bio-Environment Cont. 19(4): 351-359 (in Korean).

Masson, J., N. Trembley and A. Gosselin. 1991. Nitrogen fertilization and HPS supplementary lighting influence vegetable transplant production. I. Transplant growth. J. Amer. Soc. Hort. Sci. 116:594-598.

Meng, X.C., T. Xing and X.J. Wang. 2004. The role of light in the regulation of anthocyanin accumulation in Gerbera hybrida. J. Plant Growth Regul. 44:243- 250.

Ohashi-Kaneko, K., M. Takase, N. Kon, K. Fujiwara and K. Kurata. 2007. Effect of light quality on growth and vegetable quality in leaf lettuce, spinach and komat suna. Environ. Control Biol. 45:189-198.

Ribereau-Gayon, P. and G. Ribereau-Gayon. 1958. Influence of climateric factors on the formation and evolution of anthocyanins in fruits of grapes. Bull. Physiol. Veg. 4(1): 51-52.

Ryu, J.H. 2012. Growth and development characteristics and genetic diversity analysis of genus Taraxacum accessions collected in Korea. Sunchon National University. Ph.D. Thesis. pp. 57-61.

Ryu, J.H., K.S. Seo, Y.I. Kuk, J.H. Moon, S.K. Choi, E.S. Rha, S.C. Lee and C.H. Bae. 2012. Effects of LED (Light-Emitting Diode) treatment on antioxidant activities and functional components in Taraxacum officinale. J. Medicinal Crop Sci. 165-170.

Saebo, A., T. Krekling and M. Appelgren. 1995. Light quality affects photosynthesis and leaf anatomy of birch plantlets in vitro. Plant Cell Tissue Organ Cult. 41:177-185. 
Senger, H. 1982. The effect of blue light on plants and microorganisms. Photochemistry and Photobiol. 35:911-920.

Smith, H. 2000. Phytochromes and light signal perception by plants - An emerging synthesis. Nature 407:585-591.

Taiz, L. and E. Zeiger. 2002. Plant Physiology. Third edition. Sinauer Associates, Sunderland MA., USA. 18:375-421.

Tanaka, M., T. Takamura, H. Weatanabe, M. Endo, T. Yanagi and K. Okamoto. 1998. In vitro growth of cymbidium plantlets cultured under superbright red and blue light-emitting diodes (LEDs). Hot. Sci. \& Biotech. 73:39-44.

Zeiger, E. 1984. Blue light and stomatal function. In Senger, H. (ed.), Blue Light in Biological Systems. Springer-Verlag, Berlin, West Germany. pp. 484-494.

Zhou, Y. and B.R. Singh. 2002. Red light stimulates flowering and anthocyanin biosynthesis in American cranberry. Plant Growth Regul. 38:165-171.

(Received 27 November 2012 ; Revised 4 December 2012 ; Accepted 17 December 2012) 